\title{
50 Jahre Lebkuchenkongress - mehr als ein Grund zum Feiern!
}

Liebe Freundinnen und Freunde des Lebkuchenkongresses,

trotz des Jubiläums, an dem wir Sie alle gerne wieder persönlich getroffen hätten, muss der Lebkuchenkongress Coronabedingt noch einmal in digitaler Form stattfinden.

Der Wandel des Berufsbilds der MTR wird dieses Mal im Vordergrund stehen, alles wird digital. Darüber hinaus wollen wir Einblicke in das neue MT-Gesetz sowie den Stand der Leitlinie zur Qualitätssicherung im Röntgen und CT geben. So viel wollen wir schon verraten: Es wird sich einiges tun!

Schwerpunkt der Diagnostik und Therapie werden die unteren Extremitäten. Dabei stehen neben den Herausforderungen der Diagnostik und Therapie von akuten Sportverletzungen die Behandlungsoptionen der chronischen Schmerzzustände im Fokus. Deswegen wird zum einen die Diagnostik von Sportverletzungen thematisiert und

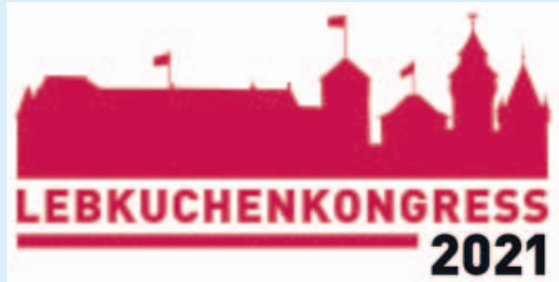

zum anderen Therapieoptionen beim schmerzhaften Gelenk vorgestellt.

In gewohnter Weise können Sie sich wieder online zum „Lebkuchenkongress 2021“ anmelden.

Seien Sie Teil des digitalen Kongressformats und unterstützen Sie uns mit Ihrer aktiven Teilnahme, um den Erfolg des Lebkuchenkongresses auch in diesem Jahr zu sichern.

In diesem Sinne heißen wir Sie schon heute sehr herzlich virtuell willkommen.

Prof. Dr. M. Lell, K. Röhr und Dr. J. Ammon
„Lebkuchenkongress 2021 DIGITAL“

Onlinefortbildung am 10. \& 11. Dezember 2021 per ZOOM

\section{Wissenschaftliche Leitung}

Dr. Josefin Ammon

Prof. Dr. Michael Lell

Katja Röhr

\section{Wissenschaftliches Komitee}

Dr. Clemens Albrecht

Dr. Torsten Fritscher

Prof. Dr. Dr. Reinhard Loose

Dr. Michael Wucherer

Alle weiteren (Anmelde-)Informationen erhalten Sie unter:

www.lebkuchenkongress.de. 